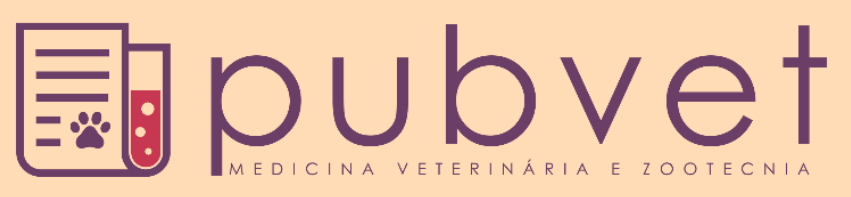

https://doi.org/10.31533/pubvet.v15n08a899.1-6

\title{
Intoxicação por metaldeído em cão: Relato de caso
}

\author{
Ana Clara Batisti Pasquali ${ }^{1} \bullet$, Jacqueline Alves $\operatorname{Itame}^{1} \bullet$, Camila Lima Rosa ${ }^{1} \bullet$, Luciana do \\ Amaral Oliveira ${ }^{1} \bullet$, Mariana Faccini Pinheiro ${ }^{1} \bullet$, Meire Christina Seki ${ }^{3} \bullet$, Adriano de Oliveira \\ Torres Carrasco $^{2 *} \bullet$ (D)
}

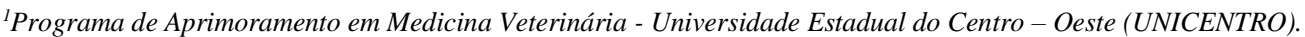

${ }^{2}$ Professor da Universidade Estadual do Centro - Oeste (UNICENTRO) - Departamento de Medicina Veterinária - Guarapuava - PR, Brasil.

${ }^{3}$ Professora da Universidade Estadual do Centro - Oeste (UNICENTRO) - Departamento de Medicina Veterinária - Guarapuava - PR, Brasil.

*Autor para correspondência: adriano.carrasco@gmail.com

Resumo. Em função do uso do veneno de caracóis (metaldeído) e pela facilidade da ingestão do mesmo pelos animais domésticos, a intoxicação de cães se torna comum. Dentre as várias alterações, as que se destacam são hipersalivação, convulsões, danos renais e hepáticos. O tratamento consiste no controle dos sinais clínicos e redução dos danos sistêmicos causados principalmente pelo estresse oxidativo. A $\mathrm{N}$-acetilcisteína, neste caso, atuou como antioxidante, tendo um papel fundamental para a recuperação do paciente.

Palavras chave: Cão, intoxicação, metaldeído, N- acetilcisteína

\section{Methaldehyde intoxication in dog: Case report}

\begin{abstract}
Due to the use of snail venom (metaldehyde) and ease of ingestion by domestic animals, the intoxication of dogs becomes common. Among the several alterations, those that stand out are hypersalivation, convulsions, renal and hepatic damages. The treatment consists of the control of the clinical signs and reduction of the systemic damages caused mainly by the oxidative stress. N-acetylcysteine, in this case, acted as an antioxidant, playing a key role in patient recovery.
\end{abstract}

Keywords: Dog, intoxication, metaldehyde, N-acetylcysteine

\section{Introdução}

Durante a estação chuvosa é comum o aumento da presença de caracóis e lesmas em jardins domésticos e, consequentemente, ocorre o acréscimo do uso de produtos para o controle destes moluscos, que são facilmente adquiridos em casas agropecuárias. Estes produtos, na sua maioria, de alto grau de toxicidade, são comercializados na forma de pellets, grânulos, pó ou líquidos, sendo o metaldeído, o princípio ativo principal. Este, usualmente é combinado com farelos, o que torna para os animais domésticos, muito atrativo e palatável (Homeida \& Cooke, 1982). No entanto, todas as espécies domésticas são sensíveis a esse princípio, correndo riscos de intoxicação aos animais, no momento que o produto é utilizado por pessoas sem a supervisão de um profissional habilitado. De uma forma geral, para as espécies domésticas, a dose tóxica varia de 0,3 a $0,8 \mathrm{mg} / \mathrm{kg}$. Os cães são a espécie com maior número de casos relatados de envenenamento por este ativo. Nesta espécie, a dose letal média (DL50) é de $100 \mathrm{mg} / \mathrm{kg}$, embora os sinais clínicos graves apareçam com doses muito menores (Reis, 2015).

O metaldeído é hidrolizado no ácido estomacal, formando polímeros de acetaldeído (Homeida \& Cooke, 1982), que são facilmente absorvidos no sistema nervoso, provocando sinais clínicos. O exato mecanismo não está elucidado; porém, este diminui as concentrações do ácido gama-aminobutírico (GABA), serotonina e norepinefrina (Maraschin, 2015; Medeiros et al., 2009). 
A manifestação dos sinais clínicos inicia-se em 15 minutos a 3 horas após a ingestão (Maraschin, 2015; Medeiros et al., 2009), sendo os sinais nervosos mais predominantes, incluindo hiperestesia, nistagmo, falta de coordenação e tremores musculares, induzidos por estímulos externos, em particular ao toque e, raramente por estímulos auditivos e visuais. Convulsões tônicas e opistótonos verificam-se nas intoxicações moderadas a graves. Também é observada dor abdominal, hiper salivação, dispneia, polipneia, taquicardia e elevação da temperatura corporal (Yas-Natan et al., 2007). No envenenamento, desenvolve-se acidose metabólica severa, resultante da biotransformação do metaldeído em acetaldeído. A morte, quando ocorre, deve-se a insuficiência respiratória, ou por complicações (incluindo insuficiência hepática) no período de três a cinco dias após a intoxicação (Maraschin, 2015; $\underline{\text { Medeiros }}$ et al., 2009).

O diagnóstico baseia-se no histórico de exposição ao fármaco, sinais clínicos e análise em laboratório do conteúdo gástrico, porém esta é uma técnica demorada e que necessita o envio do material colhido para laboratórios especializados. O metaldeído pode ser detectado no fígado, urina ou plasma (Maraschin, 2015; Medeiros et al., 2009).

De uma forma geral, o tratamento consiste em terapia de suporte e procedimentos de desintoxicação habituais, pois não há antídoto para esse componente (Reis, 2015). Quando o produto foi ingerido à menos de uma hora, pode ser realizada a indução da êmese, somado à lavagem gástrica, fornecimento de carvão ativado e protetores gástricos (Maraschin, 2015; Medeiros et al., 2009). Para controle das convulsões pode ser utilizado diazepam, anestésicos inalatórios ou barbitúricos (Yas-Natan et al., 2007). Para o controle da acidose metabólica, que comumente os pacientes envenenados apresentam, deve ser utilizado soluções cristaloides tamponadas (Maraschin, 2015; Medeiros et al., 2009). Pode ainda ser utilizada a $\mathrm{N}$-acetilcisteína, intencionando a redução do dano tecidual causado pelo envenenamento.

A N-acetilcisteína (NAC) é um composto tiólico (contendo sulfidril) com um potente efeito antioxidante (Licks, 2010). A NAC, mediante a interação com radical hidroxila e peróxido de hidrogênio, combate diretamente os radicais livres (Galvão \& Carvalho, 2014). Indiretamente a NAC age mediante a indução da síntese de glutationa, cuja a função é a remoção de radicais livres e defesa contra estresse oxidativo. Devido a essas características, a NAC é utilizada não só como agente mucolítico em uma variedade de doenças respiratórias, mas também em condições caracterizadas pelo estresse oxidativo ou pela diminuição da glutationa (Correa et al., 2014).

\section{Relato de caso}

Foi atendido na Clínica Escola Veterinária - CEVET/UNICENTRO, uma cadela, sem raça definida, fêmea, cinco meses de idade, não castrada, com peso corporal de 7,3 kg, com histórico repassado pelo proprietário de ter ingerido lesmicida, tendo como o princípio ativo o metaldeído, havia três horas. $\mathrm{O}$ paciente apresentava temperatura e frequência cardíaca dentro dos parâmetros de normalidade, pulso forte, linfonodos normopalpáveis, mucosas hipercoradas, ofegante, dor abdominal, tremores e aumento das glândulas salivares submandibulares.

O paciente foi mantido em fluidoterapia com Ringer Lactato e como o paciente havia ingerido o lesmicida a um período superior a uma hora foi ministrado carvão ativado na dose de $40 \mathrm{ml}$ por via oral, também foi fornecido omeprazol e ranitidina (ambos na dose de $1 \mathrm{mg} / \mathrm{kg}$ por via intravenosa) e administrou - se n-acetilcisteína, como antioxidante, inicialmente $140 \mathrm{mg} / \mathrm{kg}$ e posteriormente $70 \mathrm{mg} / \mathrm{kg}$ QID. O animal apresentou quadros convulsivos algumas horas após esse atendimento inicial. Para controlar o quadro ministrou - se diazempam intravenoso ( $1 \mathrm{mg} / \mathrm{kg})$; porém, como não houve melhora, optou-se por induzir o paciente ao coma com propofol na dose de $5 \mathrm{mg} / \mathrm{kg}$ e utilizando isofluorano para manutenção desse estado. O coma induzido durou cerca de 14 horas, sendo que o paciente foi retirado do plano anestésico de maneira gradativa até que não apresentasse mais episódios convulsivos.

Após oito horas da ingestão do metaldeído foi colhido sangue para realização de hemograma (Tabela 1), no qual foi detectado anemia e trombocitopenia (achado justificado por problemas na colheita da amostra) e perfil bioquímicos (Tabela 3), nos quais a diminuição da proteína total plasmática e o aumento da transaminase oxalacética (AST) foram as alterações observadas, também foi colhida urina para realização de urinálise, na amostra que apresentava cor marrom clara se observou hemoglobinúria, proteinúria e presença de cilindros granulosos. Repetiu-se esses mesmos 
exames, exceto a urinálise, após 24 horas e sete dias da ingestão do veneno (Tabela 3). Um dia após a intoxicação, o paciente ainda apresentava aumento da transaminase oxalacética e da transaminase pirúvica. Após sete dias os parâmetros avaliados se encontravam dentro dos valores de referência para a espécie.

Foi realizada ultrassonografia abdominal no sétimo dia após a ingestão do composto, constatando alteração hepática (observou - se que o parênquima do fígado se encontrava hiperecogênico).

Nesse mesmo dia o paciente pode ser levado para casa pelos tutores, retornando 15 dias após a liberação do internamento para avaliação apresentando bom estado geral. Quatro meses após o episódio de intoxicação o animal retornou para consulta e realização de exames laboratoriais (Tabela 1 e $\underline{3}$ ), sendo que nessa nova avaliação constatou-se que o paciente se encontrava com todos os parâmetros dentro da normalidade.

\section{Discussão}

Com base no histórico e evolução do caso, não foi induzido a êmese, já que o paciente havia ingerido a mais de uma hora o metaldeído. Isto posto, para minimizar a absorção foi utilizado carvão ativado (40 $\mathrm{ml} \mathrm{VO}$ ) por ser um adsorvente, e possui capacidade de se ligar ao agente tóxico, formando um composto estável que não é absorvido pelo trato gastrointestinal, sendo eliminado pelas fezes (Xavier et al., 2007).

Como protetores gástricos foram utilizados tanto o omeprazol (1 mg/kg IV) quanto a ranitidina (1 $\mathrm{mg} / \mathrm{kg} \mathrm{IV}$ ), pois agem em diferentes pontos diminuindo a secreção ácida gástrica, sendo o primeiro fármaco um inibidor da bomba de prótons e o segundo um antagonista de receptores de histamina (Maddison et al., 2010).

A fluidoterapia de escolha foi o Ringer com Lactato, já que pacientes envenenados por metaldeído apresentam acidose metabólica e este fluido proporciona uma elevação do $\mathrm{pH}$ em líquidos extracelulares, agindo nos casos em que há um desvio do equilíbrio ácido-básico no sentido da acidose (Cosenza et al., 2015). Como antioxidante foi utilizado a n-acetilcisteína (dose inicial $140 \mathrm{mg} / \mathrm{kg}$ e posteriormente $70 \mathrm{mg} / \mathrm{kg}$ QID), combatendo diretamente os radicais livres e aumentando as concentrações de glutationa (Ondani et al., 2011). Tal protocolo foi extremamente benéfico, já que os exames laboratoriais para avaliação da função hepática realizados nos dias seguintes ao quadro de intoxicação apresentaram melhoras significativas.

Horas após o atendimento inicial, o animal evoluiu para quadros convulsivos, sendo administrado diazepam $(1 \mathrm{mg} / \mathrm{kg} \mathrm{IV})$, pois este agente causa inibição da neurotransmissão ao nível dos neurônios internunciais na medula espinhal, promovendo relaxamento muscular e controle da convulsão (Natalini, 2007). Todavia, este fármaco não foi efetivo para esta finalidade e o animal permaneceu em quadro convulsivo. Sendo assim, foi necessária a indução ao coma com propofol $(5 \mathrm{mg} / \mathrm{kg})$, utilizando-se para a manutenção o isoflurano. A escolha deste anestésico inalatório se deve a necessidade urgente do controle das convulsões, com base na ausência de resposta ao diazepan. Por conseguinte, devido ao fato da excreção deste agente anestésico inalatório não ocorre pelas vias renal ou hepática, objetivamos um efeito de proteção frente as possíveis lesões nesses órgãos. Ademais, a taxa de biotransformação do isoflurano é extremamente baixa $(0,2 \%)$, portanto a maior parte da quantidade do anestésico inalado é exalado inalterado (Maddison et al., 2010). Foi retirado o animal do plano anestésico gradativamente até não apresentar mais quadros de convulsão, totalizando 14 horas de coma induzido. O paciente ficou internado durante sete dias recebendo fluidoterapia e os medicamentos previamente descritos, exceto a ranitidina que foi interrompida no segundo dia de internamento.

Foram realizados exames laboratoriais oito horas após a ingestão do veneno. No hemograma (Tabela 1) observou anemia, decorrente possivelmente a problemas nutricionais, e a trombocitopenia, por problemas na colheita do material, fato já descrito por Bush (1991), o qual relata diversas causas entre elas aglutinação plaquetária e erros na coleta. Na avaliação dos perfis bioquímicos (Tabela 2), os mesmos apresentaram diminuição da proteína total plasmática e aumento da transaminase oxalacética (AST), já evidenciando danos hepáticos. 
Tabela 1. Resultados de hemograma, leucograma e plaquetas do animal com intoxicação por metaldeído atendido na clínica escola veterinária - UNICENTRO nos dias 0,7 e 120 pós intoxicação.

\begin{tabular}{lccc}
\hline Hemograma & Dia 0 & Dia 7 & Dia 120 \\
\hline Eritrócitos & 5,34 milhões $/ \mathrm{mm}^{3}$ & 6,46 milhões $/ \mathrm{mm}^{3}$ & $6,46 \mathrm{milhões} / \mathrm{mm}^{3}$ \\
Hemoglobina & $11,6 \mathrm{~g} / \mathrm{Dl}$ & $14,8 \mathrm{~g} / \mathrm{Dl}$ & $14,91 \mathrm{~g} / \mathrm{Dl}$ \\
Hematócrito & $35,9 \%$ & $43,7 \%$ & $43,92 \%$ \\
& & & \\
\hline Leucograma & & & $6670 / \mathrm{mm}^{3}$ \\
\hline Leucócitos & $6200 / \mathrm{mm}^{3}$ & $12790 / \mathrm{mm}^{3}$ & $200 / \mathrm{mm}^{3}$ \\
Bastonetes & $62 / \mathrm{mm}^{3}$ & $127 / \mathrm{mm}^{3}$ & $3669 / \mathrm{mm}^{3}$ \\
Segmentados & $1674 / \mathrm{mm}^{3}$ & $10104 / \mathrm{mm}^{3}$ & $800 / \mathrm{mm}^{3}$ \\
Eosinófilos & $62 / \mathrm{mm}^{3}$ & $254 / \mathrm{mm}^{3}$ & $1734 / \mathrm{mm}^{3}$ \\
Linfócitos típicos & $4030 / \mathrm{mm}^{3}$ & $2302 / \mathrm{mm}^{3}$ & $267 / \mathrm{mm}^{3}$ \\
Monócitos & $0 / \mathrm{mm}^{3}$ & $372 / \mathrm{mm}^{3}$ & $197600 / \mathrm{mm}^{3}$ \\
Plaquetas & $135000 / \mathrm{mm}^{3}$ & $93000 / \mathrm{mm}^{3}$ &
\end{tabular}

Tabela 2. Resultados Bioquímicos do animal com intoxicação por metaldeído atendido na clínica escola veterinária UNICENTRO nos dias 0,7 e 120 pós intoxicação.

\begin{tabular}{lcccc}
\hline Bioquímicos & Dia 0 & Dia 2 & Dia 7 & Dia 120 \\
\hline Ureia & $31,1 \mathrm{mg} / \mathrm{dL}$ & $27,5 \mathrm{mg} / \mathrm{dL}$ & $37,8 \mathrm{mg} / \mathrm{dL}$ & $28 \mathrm{mg} / \mathrm{dL}$ \\
Fosfatase Alcalina & $114 \mathrm{UI} / \mathrm{L}$ & $230,1 \mathrm{UI} / \mathrm{L}$ & $156,2 \mathrm{UI} / \mathrm{L}$ & $44,1 \mathrm{UI} / \mathrm{L}$ \\
Albumina & $2,9 \mathrm{~g} / \mathrm{dL}$ & $3 \mathrm{~g} / \mathrm{dL}$ & $2,9 \mathrm{~g} / \mathrm{dL}$ & $3,2 \mathrm{~g} / \mathrm{dL}$ \\
Creatinina & $0,5 \mathrm{mg} / \mathrm{dL}$ & $0,6 \mathrm{mg} / \mathrm{Dl}$ & $0,5 \mathrm{mg} / \mathrm{dL}$ & $0,9 \mathrm{mg} / \mathrm{dL}$ \\
Transaminase Pirúvica (ALT) & $42 \mathrm{UI} / \mathrm{L}$ & $75,70 \mathrm{UI} / \mathrm{L}$ & $61,50 \mathrm{UI} / \mathrm{L}$ & $45,70 \mathrm{UI} / \mathrm{L}$ \\
Gama Glutamil Transferase & $3,1 \mathrm{UI} / \mathrm{L}$ & $3,1 \mathrm{UI} / \mathrm{L}$ & $2 \mathrm{UI} / \mathrm{L}$ & $*$ \\
Proteínas totais & $4,4 \mathrm{~g} / \mathrm{dL}$ & $4,5 \mathrm{~g} / \mathrm{Dl}$ & $4,9 \mathrm{~g} / \mathrm{dL}$ & $*$ \\
Transamisane Oxalacética (AST) & $58,6 \mathrm{UI} / \mathrm{L}$ & $193,1 \mathrm{UI} / \mathrm{L}$ & $42,9 \mathrm{UI} / \mathrm{L}$ & $*$ \\
\hline
\end{tabular}

*Não foi solicitado.

Na urinálise (Tabela 3) observou-se urina marrom clara com hemoglobinúria pela disfunção no fígado (Bush, 1991), proteinúria causada pelo quadro de convulsões, sendo caracterizada por proteinúria pré-renal, aonde as causas são variadas desde febre, exercícios musculares intensos, hipertensão glomerular e até convulsões (Tilley et al., 2008), além de cilindros granulosos mostrando degeneração tubular aguda, já relatada por González \& Silva (2008), os quais relacionam cilindros granulosos com a presença de lesão renal aguda, principalmente na região tubular.

Tabela 3. Resultado da urinálise do animal com intoxicação por metaldeído atendido na Clínica Escola Veterinária CEVET/UNICENTRO realizado no dia da ingestão do lesmicida.

\begin{tabular}{lc}
\hline Urinálise & $14 / 09 / 16$ \\
\hline Volume & $10 \mathrm{ml}$ \\
Cor & Marrom claro/ avermelhado \\
Aspecto & Límpido \\
Densidade & 1020 \\
pH & 6,5 \\
Proteínas & + \\
Hemoglobina & +++ \\
Glicose & - \\
Acetona & - \\
Bilirrubina & - \\
Urobilinogênio & - \\
Sedimento & \\
Leucócitos & 0 \\
Hemácias & $01 /$ campo \\
Cilindros Hialinos & 0 \\
Cilindros Granulosos & Presença \\
Cilindros Hemáticos & 0 \\
\hline
\end{tabular}

Repetiu-se os exames de sangue 24 horas e sete dias após o quadro de intoxicação (Tabela 3 ) sendo evidenciados aumento da transaminase oxalacética e da transaminase pirúvica mostrando uma injúria 
no fígado, em contrapartida, o retorno dos parâmetros dentro da normalidade em cerca de sete dias demonstrou um prognóstico favorável. $\mathrm{O}$ aumento dos valores referentes a fosfatase alcalina mostrou uma colestase, sendo essa enzima o mais sensível indicador desse tipo de injúria, pois se desenvolve antes que haja qualquer aumento de bilirrubina. Também a hipoproteinemia demonstrou um dano hepático transitório. Entretanto, com um aumento progressivo da proteína sérica, neste caso, mostrou regeneração do órgão normalizando a sintetização da mesma (․ㅡsh, 1991).

A ultrassonografia abdominal foi realizada uma semana após o atendimento clínico. Neste exame, todos os órgãos apresentaram-se normais, exceto o fígado que apresentou parênquima hiper ecogênico, sendo comum em hepatopatias crônicas, cirrose e alguns tipos de neoplasias (Garcia et al., 2012). O resultado do exame ultrassonográfico foi compatível com os resultados obtidos na avaliação bioquímica.

O paciente foi liberado após sete dias de internamento com prescrição de Omeprazol $(1 \mathrm{mg} / \mathrm{kg}$ VO SID), Hemolitan ${ }^{\circledR}$ (0,2 ml/kg VO BID), Hepvet ${ }^{\circledR}$ (2 gotas $/ \mathrm{kg}$ VO SID) e Silimarina (50 mg/kg VO SID). Retornou 15 dias após a consulta, apresentando bom estado geral e todos os parâmetros dentro da normalidade para a espécie, recebendo alta médica. Quatro meses após a intoxicação o animal retornou para realização de exames laboratoriais (Tabelas 1 e $\underline{3}$ ) os quais mostraram todos os parâmetros dentro das normalidades.

\section{Conclusão}

A intoxicação por metaldeído requer intervenção médica imediata com tratamento suporte, controlando principalmente os sinais clínicos relacionados ao sistema nervoso central, como as convulsões, e os danos renais e hepáticos que levam a complicações posteriores, caso não revertidos, resultando no óbito do paciente. A utilização da $\mathrm{N}$-acetilcisteína teve um papel importante na recuperação dos órgãos afetados já que atuou como antioxidante, reduzindo o estresse oxidativo, fazendo com que menos células fossem lesadas, ocasionando a melhora do quadro clínico do animal.

\section{Referências}

Bush, B. M. (1991). Interpretation of laboratory results for small animal clinicians. Blackwell Scientific Publications Ltd.

Correa, M. J. U., Mariz, H. A., Andrade, L. E. C., \& Kayser, C. (2014). N-acetilcisteína oral no tratamento do fenômeno de Raynaud secundário à esclerose sistêmica: ensaio clínico randomizado, placebo-controlado e duplo-cego. Revista Brasileira de Reumatologia, 54(6), 452-458. https://doi.org/10.1016/j.rbr.2014.07.001.

Cosenza, M., Pereira, P. F. V, Romão, F., Flaiban, K., Fernandes, L. I., Gargano, R. G., \& Lisbôa, J. A. N. (2015). Efeito alcalinizante da solução de Ringer com lactato em ovelhas sadias e acidóticas. Arquivo Brasileiro de Medicina Veterinária e Zootecnia, 67(3), 855-863. https://doi.org/10.1590/1678-4162-6501.

Galvão, A. L. B., \& Carvalho, M. B. (2014). Perfil hepático e eletrolítico de cães idosos sadios ou com doença renal crônica tratados com o antioxidante n-acetilcisteína. Archives of Veterinary Science, 19(2), 9-14. https://doi.org/10.5380/avs.v19i2.33156.

Garcia, D. A. A., Froes, T. R., \& Guérios, S. D. (2012). Ultrassonografia abdominal pré-operatória em cães e gatos com suspeita de tumores abdominais. Ciência Rural, 42(1), 105-111. https://doi.org/10.1590/S0103-84782012000100017.

González, F. H. D., \& Silva, S. C. (2008). Patologia clínica veterinária: texto introdutório. Universidade Federal do Rio Grande do Sul.

Homeida, A. M., \& Cooke, R. G. (1982). Pharmacological aspects of metaldehyde poisoning in mice. Journal of Veterinary Pharmacology and Therapeutics, 5(1), 77-81. https://doi.org/10.1111/j.13652885.1982.tb00500.x.

Licks, F. (2010). Ação antioxidante da N-acetilcisteína (NAC) na gastropatia da hipertensão portal. Universidade Federal do Rio Grande do Sul.

Maddison, J. E., Page, S. W., \& Church, D. B. (2010). Farmacologia clínica em pequenos animais. Elsevier Brasil. 
Maraschin, D. K. (2015). Intoxicações em cães. In Medicina Veterinária: Vol. PhD. Universidade Federal do Rio Grande do Sul.

Medeiros, R. J., Monteiro, F. O., Castelo da Silva, G., \& Nascimento Júnior, A. (2009). Casos de intoxicações exógenas em cães e gatos atendidos na Faculdade de Veterinária da Universidade Federal Fluminense durante o período de 2002 a 2008. Ciência Rural, 39(7), 2105-2110.

Natalini, C. C. (2007). Teoria e técnicas em anestesiologia veterinária. Srtmed.

Ondani, A. C., Carvalho, M. B., \& Galvão, A. L. B. (2011). N-acetilcisteína-ação antioxidante e utilização na clínica de pequenos animais. Archives of Veterinary Science, 16(2). https://doi.org/10.5380/avs.v16i2.17774.

Reis, J. (2015). Protocolos Clínicos-Diagnóstico e intervenção em clínica de animais de companhia. Universidade de Évora-disponibilizado via Moodle.

Tilley, L. P., Smith, J. R., \& Francis, W. K. (2008). Consulta veterinária em 5 minutos: Espécies canina e felina. Editora Manole.

Xavier, F. G., Righi, D. A., \& Spinosa, H. S. (2007). Toxicologia do praguicida aldicarb (“chumbinho"): aspectos gerais, clínicos e terapêuticos em cães e gatos. Ciência Rural, 37(4), 1206-1211. https://doi.org/10.1590/s0103-84782007000400051.

Yas-Natan, E., Segev, G., \& Aroch, I. (2007). Clinical, neurological and clinicopathological signs, treatment and outcome of metaldehyde intoxication in 18 dogs. Journal of Small Animal Practice, 48(8), 438-443. https://doi.org/10.1111/j.1748-5827.2007.00360.x.

Histórico do artigo:

Recebido: 1 de abril de 2021

Aprovado: 3 de maio de 2021
Licenciamento: Este artigo é publicado na modalidade Acesso Aberto sob a licença Creative Commons Atribuição 4.0 (CC-BY 4.0), a qual permite uso irrestrito, distribuição, reprodução em qualquer meio, desde que o autor e a fonte sejam devidamente creditados. 